\title{
Steam Performance of UB2/U3Si2 Composite Fuel Pellets, Compared to U3Si2 Reference Behaviour
}

DOI:

10.1016/j.jnucmat.2019.151919

Document Version

Accepted author manuscript

Link to publication record in Manchester Research Explorer

\section{Citation for published version (APA):}

Turner, J., \& Abram, T. (2020). Steam Performance of UB2/U3Si2 Composite Fuel Pellets, Compared to U3Si2 Reference Behaviour. J. Nucl. Mater., 529, [151919]. https://doi.org/10.1016/j.jnucmat.2019.151919

\section{Published in:}

J. Nucl. Mater.

\section{Citing this paper}

Please note that where the full-text provided on Manchester Research Explorer is the Author Accepted Manuscript or Proof version this may differ from the final Published version. If citing, it is advised that you check and use the publisher's definitive version.

\section{General rights}

Copyright and moral rights for the publications made accessible in the Research Explorer are retained by the authors and/or other copyright owners and it is a condition of accessing publications that users recognise and abide by the legal requirements associated with these rights.

\section{Takedown policy}

If you believe that this document breaches copyright please refer to the University of Manchester's Takedown Procedures [http://man.ac.uk/04Y6Bo] or contact uml.scholarlycommunications@manchester.ac.uk providing relevant details, so we can investigate your claim.

\section{OPEN ACCESS}




\title{
Steam Performance of $\mathrm{UB}_{2} / \mathrm{U}_{3} \mathrm{Si}_{2}$ Composite Fuel Pellets, Compared to $\mathrm{U}_{3} \mathrm{Si}_{2}$ Reference Behaviour
}

\author{
Turner, J, Abram, T.J. \\ Nuclear Fuel Centre of Excellence, The University of Manchester, United Kingdom
}

\begin{abstract}
Uranium diboride $\left(\mathrm{UB}_{2}\right)$ was produced via arc melting and mixed with $\mathrm{U}_{3} \mathrm{Si}_{2}$ material via coldpress and sintering. Composite materials, from $0-100 \% \mathrm{UB}_{2}$ were placed in high temperature flowing steam and mass gain observed. It was seen that the addition of $10 \mathrm{wt} \% \mathrm{UB}_{2}$ to $\mathrm{U}_{3} \mathrm{Si}_{2}$ increased the onset of reaction by $100{ }^{\circ} \mathrm{C}$ compared to pure $\mathrm{U}_{3} \mathrm{Si}_{2}$ in the same conditions. 50 $\mathrm{wt} \% \mathrm{UB}_{2} / \mathrm{U}_{3} \mathrm{Si}_{2}$ pellets maintained this increase, alongside a significant reduction in the ejection of material typically seen in $\mathrm{U}_{3} \mathrm{Si}_{2}$-steam reactions. From these results, a mechanism for both composite reaction and the performance of $\mathrm{U}_{3} \mathrm{Si}_{2}$ in steam is proposed.
\end{abstract}

Keywords: Nuclear Fuel, Accident Tolerant Fuel, Uranium silicide, Uranium boride

\section{Introduction}

Accident tolerant fuels (ATFs) are the current subject of a wide ranging international research effort. ATFs include a range of alternative claddings and high-density fuel materials, with the aim to reduce stored energy in the fuel, reduce enrichment requirements, and eliminate the potential for hydrogen production during severe accidents. Uranium silicide fuel, specifically the $\mathrm{U}_{3} \mathrm{Si}_{2}$ phase, is of interest as an ATF material due to a high thermal conductivity, uranium density and compatibility with ceramic cladding concepts [1]. However, recent results suggest that $\mathrm{U}_{3} \mathrm{Si}_{2}$ undergoes a rapid and energetic reaction with high temperature steam [2]. This reaction is so energetic that measuring mass gain is problematic due to material ejection during the experiment.

As an alternative, uranium diboride $\left(\mathrm{UB}_{2}\right)$ has several advantages; a high uranium density $\left(11.7 \mathrm{~g} / \mathrm{cm}^{3}\right)$ [3], good predicted thermal conductivity [4] and greater resistance to high temperature water/steam than both $\mathrm{U}_{3} \mathrm{Si}_{2}$ or uranium nitride fuel materials [5]. Historically $\mathrm{UB}_{2}$ has received limited interest, as boron is a strong thermal neutron absorber. However, the commercial production of enriched boron- 10 for use in control rods necessarily produces material enriched in boron-11 as a by-product, which has a very small neutron cross section. There is currently renewed interest in $\mathrm{UB}_{2}$ fuel concepts, most notably though atomic scale modelling to predict physical properties $[4,6]$.

The creation of a composite $\mathrm{U}_{3} \mathrm{Si}_{2}$ and $\mathrm{UB}_{2}$ material is of interest for two reasons; it offers the potential to improve overall water performance of $\mathrm{U}_{3} \mathrm{Si}_{2}$ while maintaining a high uranium density, and the provision of a distributed burnable poison within $\mathrm{U}_{3} \mathrm{Si}_{2}$ which does not disrupt the uranium bearing phase (achieved by varying the boron-10 to boron-11 ratio). Burnable poisons in $\mathrm{U}_{3} \mathrm{Si}_{2}$ may be problematic with alternative solutions explored to date proving unstable or incompatible with $\mathrm{U}_{3} \mathrm{Si}_{2}$ [7]. Maintaining some silicide component within the fuel may be of 
interest to reduce the economic penalty that arises from the need to use enriched boron within $\mathrm{UB}_{2}$.

The performance of a composite $\mathrm{UB}_{2} / \mathrm{U}_{3} \mathrm{Si}_{2}$ material under high temperature steam has been investigated to determine if it offers any improvements compared to reference $\mathrm{U}_{3} \mathrm{Si}_{2}$ and to develop a greater understanding of the $\mathrm{U}_{3} \mathrm{Si}_{2}$-steam reaction.

\subsection{Methodology}

Composite discs were produced based on the general manufacturing route for $\mathrm{U}_{3} \mathrm{Si}_{2}$ pellets [8]. A small amount ( $<5$ at $\%)$ of a $\mathrm{UO}_{0.75} \mathrm{C}_{0.25}$ phase was distributed throughout the composite pellets, which formed as a result of a small fraction of uranium metal present in the arc melted $\mathrm{UB}_{2}$. This phase was observed in $\mathrm{UB}_{2}$ following high energy milling in a tungsten carbide milling vessel and was assumed to have formed as a result of uranium metal interacting with the carbide walls. It did not appear to increase in mass fraction following production of composite pellets. Carbide phases are known to be highly reactive with water even at low temperatures and so the material containing this phase was considered to form a lower bound of steam performance. Material successfully produced without carbide inclusions could be expected to show improved steam performance at similar temperatures. The manufacture of these composite materials is detailed more completely in [9].

For steam testing, fragments were mechanically broken from the sample and placed in a cylindrical alumina crucible (approx $6 \mathrm{~mm}$ x $6 \mathrm{~mm}$ ). Thermogravimetry (TGA) was performed using a Netzsch 449-STA 'Jupiter' F1. Samples were brought to $250{ }^{\circ} \mathrm{C}$ in flowing argon and held for 10 minutes before introducing flowing steam at a rate of $5 \mathrm{~g} / \mathrm{hr}$ while maintaining argon flow. The furnace temperature was increased to $1000^{\circ} \mathrm{C}$ at a rate of $20^{\circ} \mathrm{C} / \mathrm{min}$. Furnace temperature was controlled to within $5^{\circ} \mathrm{C}$, while sample temperature was monitored and is reported here.

Previous work on the silicide-steam reaction has highlighted the importance of crucible size and shape [2]. It was suggested by Sooby Wood that deep crucibles hinder the reaction via the production of a localised atmosphere around the sample. This was examined via the use of zirconium sponge as a test sample, which was seen to undergo a reduced reaction within the standard deep crucible supplied.

A similar test was performed on zirconium sponge samples within the present work and compared to the modified crucible employed by Sooby Wood (Figure 1). The earlier onset temperature and greater overall mass gain observed in the present work suggest that the crucible employed does not inhibit the steam reaction.

The straight walled crucible used here was preferred in an effort to limit mass loss events which were expected when exposing $\mathrm{U}_{3} \mathrm{Si}_{2}$ to steam at these temperatures. The fragments tested were relatively small and placed at the bottom of the crucible, thus limiting the ejection angles which could remove sample mass from the crucible entirely.

Samples were examined via X-ray Diffraction (XRD, Panalytical Empyrian) and Scanning Electron Microscopy (SEM, FEI Nova NanoSEM). XRD was performed on powder produced via crushing samples in an agate pestle and mortar.

For clarity within the present work we describe samples which have been exposed to steam as 'oxidised', as the end product from this reaction is $\mathrm{UO}_{2}$. This is not intended to imply that the only reaction occurring is that of oxidation. 


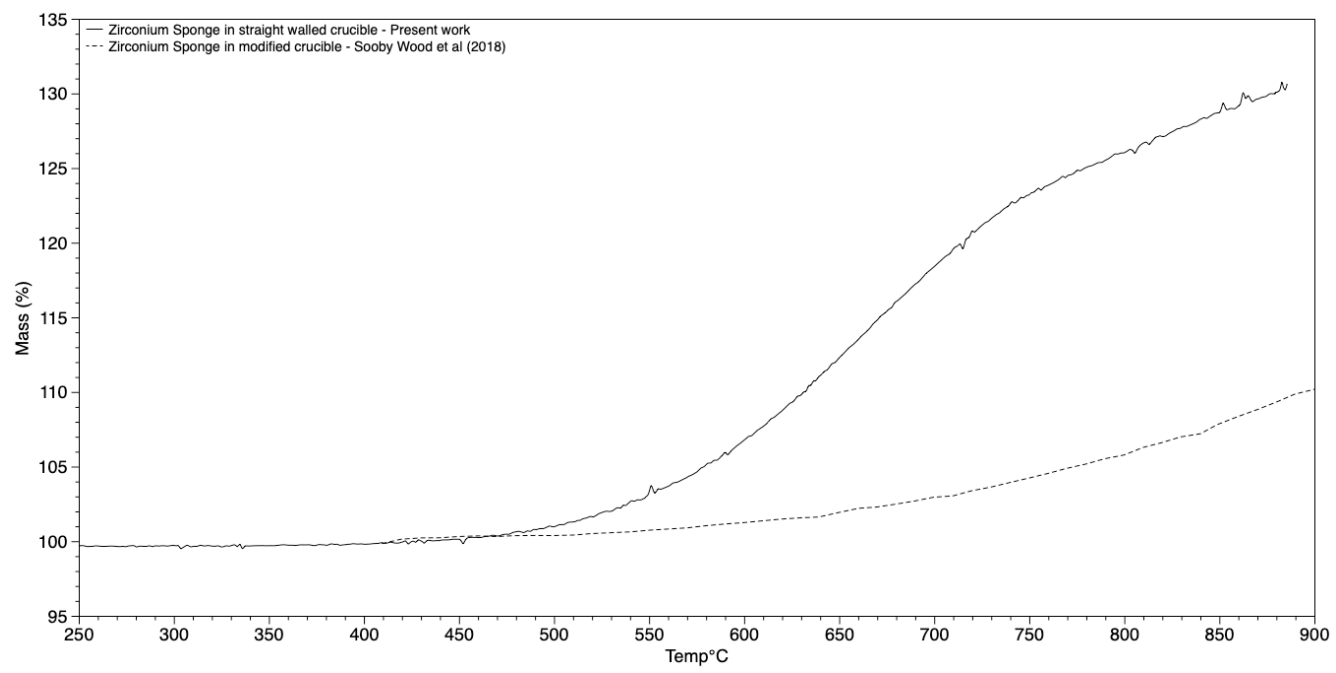

Figure 1: Test exposure of zirconium sponge to steam within the crucibles employed from the present work, the rapid reaction suggests that the crucible geometry employed does not hinder the reaction noticeably. Included for comparison is the data on zirconium sponge oxidation in a modified crucible, reproduced from Sooby Wood et al [2]

\begin{tabular}{|c|c|}
\hline Material & Onset Temperature $\left({ }^{\circ} \mathrm{C}\right)$ \\
\hline $\mathrm{U}_{3} \mathrm{Si}_{2}$ & $453,449 *$ \\
$\mathrm{UB}_{2}$ & 629 \\
$50 \mathrm{wt} \% \mathrm{UB}_{2}$ Composite & 548,575 \\
$10 \mathrm{wt} \% \mathrm{UB}_{2}$ Composite & $553^{*}$ \\
\hline
\end{tabular}

Table 1: Temperatures at which rapid mass changes were observed for materials listed. * denotes a determination made manually and not using the automated software routine

\section{Results}

\subsection{Thermogravimetry}

Figure 2 shows the change in mass for samples exposed to flowing steam between $250^{\circ} \mathrm{C}$ and $900^{\circ} \mathrm{C}$. For reference, data from [2] is also shown. In line with existing literature on the silicide-steam reaction, percent mass changes are reported here rather than normalising reaction rates to surface area, due to material loss which was observed on some measurements. Spikes visible on the data are due to water condensing at the outlet of the furnace, temporarily preventing flow. Although these have been numerically smoothed using the Netzsch Proteus software, small sharp peaks on the plots remained. Where possible onset temperatures were calculated from this analysis software and are presented in Table 1 . In some cases (denoted * in Table 1) peaks caused by condensation prevented this, and a best estimate was made manually.

Onset of the silicide reaction appears to be in good agreement with the literature $\mathrm{U}_{3} \mathrm{Si}_{2}$ reaction, although the response is different as limited material ejection was observed within the present work. Data in the magnified inset of Figure 2 shows a slight increase in mass of $\mathrm{U}_{3} \mathrm{Si}_{2}$

samples examined as a function of the present work, while the literature data begins to lose mass, likely as a result of small mass ejection events. The slightly deeper crucible employed within this 


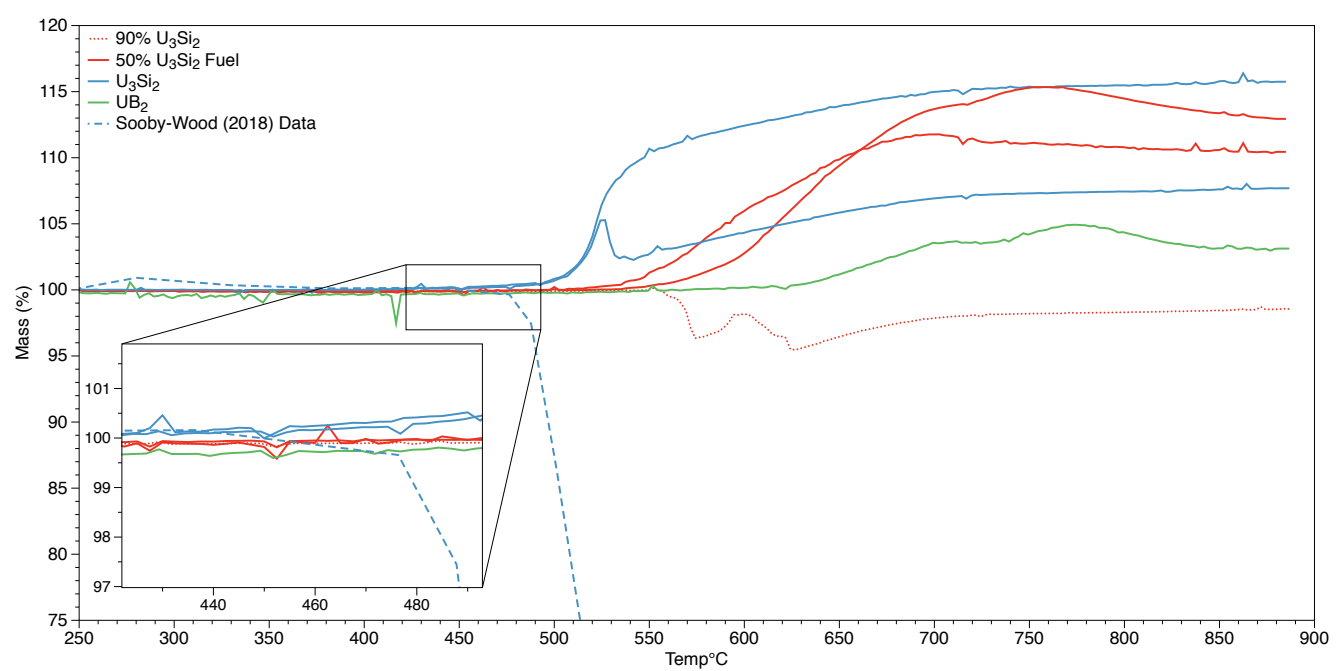

Figure 2: Thermogravimetry of composite and reference fuel materials in flowing steam

work appears to have limited the outright loss of material. A mass loss event is visible on one $\mathrm{U}_{3} \mathrm{Si}_{2}$ reference sample, although at a higher temperature than previously published data. We consider this data to be in good agreement with published data given that the crucibles are more likely to retain fragments due to their vertical walls, and the mass uptake observed in Figure 2 correlates well with the temperature of ejection previously reported.

$50 \mathrm{wt} \% \mathrm{UB}_{2}$ content has a significant increase in onset temperature compared to the reference silicide material. Very slow mass gain is observed between 500 and $550{ }^{\circ} \mathrm{C}$ for these samples, before the onset of a more complicated multi-stage mass gain reaction, culminating in mass loss above $750{ }^{\circ} \mathrm{C}$.

This is similar to the behaviour observed in the reference $\mathrm{UB}_{2}$ sample; a three stage reaction, with an inflection point around $725^{\circ} \mathrm{C}$ and mass loss above $750{ }^{\circ} \mathrm{C}$. The composite fuel begins to react at a lower temperature than $\mathrm{UB}_{2}$, but significantly above the $\mathrm{U}_{3} \mathrm{Si}_{2}$ onset temperature. It's behaviour varies from that which would be expected if both constituents were reacting separately, and very limited mass gain is observed until above the temperature at which the pure $\mathrm{U}_{3} \mathrm{Si}_{2}$ reaction with steam has plateaued. The variation in sample behaviour visible between the two $50 \mathrm{wt} \%$ composites is likely due to differences in surface area to volume ratio, as the fragments varied in shape and size.

\subsection{X-ray Diffraction}

All XRD patterns from material following exposure to $900^{\circ} \mathrm{C}$ steam show only the production of $\mathrm{UO}_{2}$. No compounds of boron or silicon were observed (Figure 3 ) aside from a very small quantity of $\mathrm{UB}_{2}$ which remained within the 50-50 composite material (highlighted as ' $*$ ' on Figure 3). This suggests that either any silicon and boron compounds that formed were volatilised and escaped the sample, or that amorphous compounds were formed that cannot be detected by XRD. 


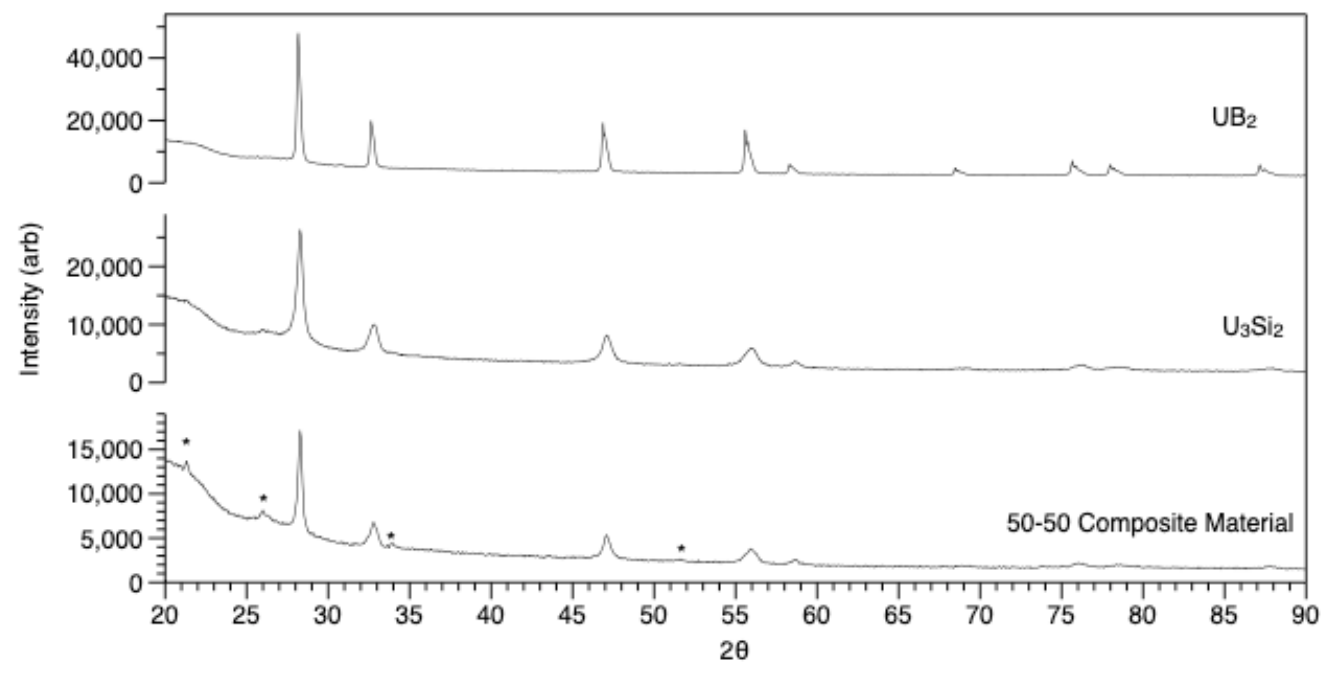

Figure 3: XRD analysis of materials following exposure to high temperature steam. All peaks aside from those denoted * represent $\mathrm{UO}_{2}$. Peaks marked with * indicate very small amounts of remaining $\mathrm{UB}_{2}$

\subsection{Microscopy}

Electron microscopy consisted of three sample sets; material which had not been exposed to steam, material briefly exposed to steam at one of two fixed temperatures, and powdered material produced from exposure to $900{ }^{\circ} \mathrm{C}$ steam.

\subsubsection{Non-Exposed Materials}

Figure 4 shows a $50 \mathrm{wt} \%$ composite $(\mathrm{A})$, sintered $\mathrm{UB}_{2}$ microstructure (B) and reference $\mathrm{U}_{3} \mathrm{Si}_{2}$ (C) which have not been exposed to steam.

Figure $4 \mathrm{C}$ shows a region representative of the bulk sintered $\mathrm{U}_{3} \mathrm{Si}_{2}$ material produced for this study. One region of the produced pellet showed significant porosity along the edge of the pellet (Figure 5) which may result from the pellet being placed in contact with an oxygen getter (tantalum foil) during sintering. The presence of porosity in steam-corroded $\mathrm{U}_{3} \mathrm{Si}_{2}$ was therefore not treated as conclusive evidence of reaction, despite the apparent similarity between pores on Figure 5 and evidence of corrosion presented in [2].

In line with the expected sintering performance of the $\mathrm{U}_{3} \mathrm{Si}_{2}$ powder employed, which was several weeks old at the time of sample production, a number of oxide regions are also visible within the non-exposed material. These were identified as localised grains of $\mathrm{UO}_{2}$, and proved relatively easy to distinguish from oxide produced from interaction with steam as a result of their morphology. The oxide phase present in the non-exposed samples formed small circular regions, typically around $5 \mu \mathrm{m}$ in diameter.

Figure 4 A shows the microstructure of a $50 \mathrm{wt} \%$ composite pellet. Regions of $\mathrm{U}_{3} \mathrm{Si}_{2}$ (lighter) and $\mathrm{UB}_{2}$ (darker, rectangular) are distinguishable, as are small grains of UCO phase discussed earlier. The density of the composite material was similar to the reference $\mathrm{U}_{3} \mathrm{Si}_{2}$ material, and appears to be an artefact of the age of the silicide powder used to produce the composites. This is thought to result from the formation of an oxide layer during storage, even in the sub-ppm 


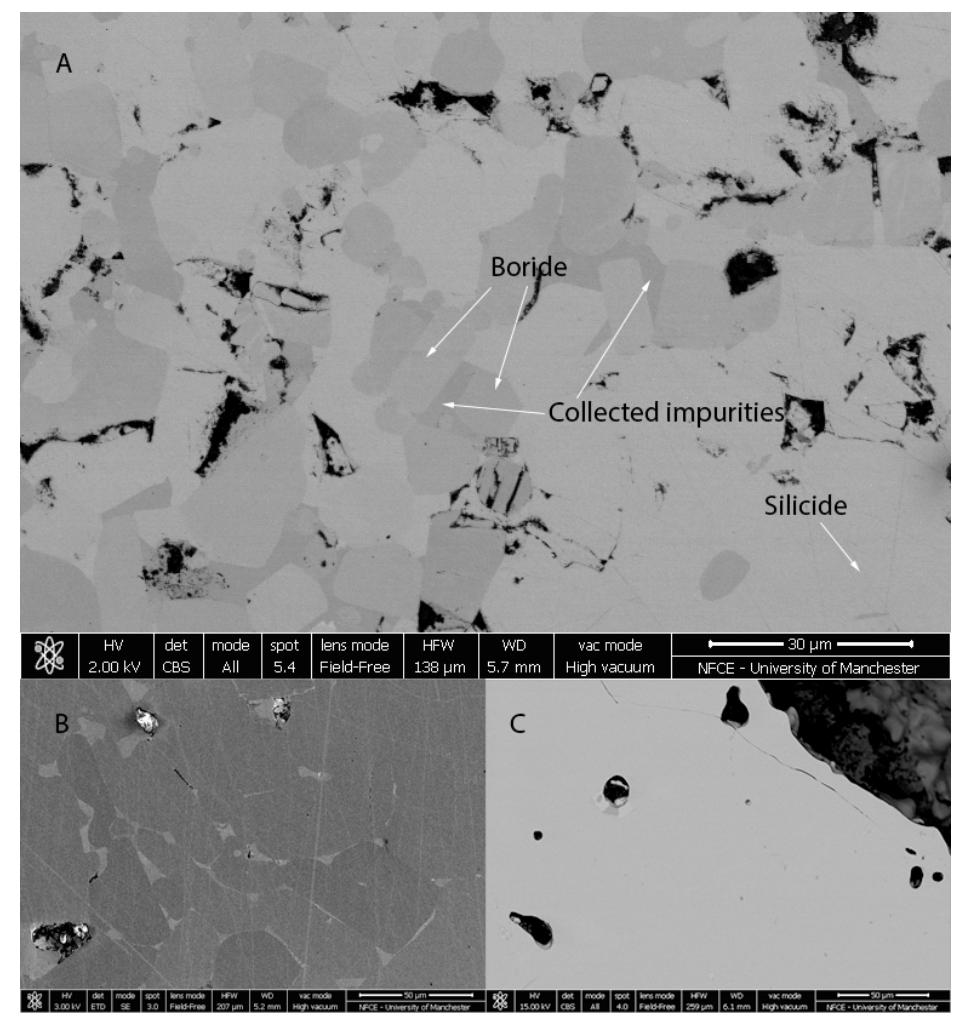

Figure 4: A - Microstructure of 50wt \% composite material. B - UB $2 . \mathrm{C}-\mathrm{U}_{3} \mathrm{Si}_{2}$. All produced materials show some secondary phase impurities porosity, generally resulting from the age of the silicide powder employed or the presence of UCO

$\mathrm{O}_{2}$ environment of the inert argon gloveboxes employed here. There is no detectable interaction layer between the boride and silicide phases following sintering.

Figure $4 \mathrm{~B}$ is representative of the sintered $\mathrm{UB}_{2}$ microstructure, which contains grains of $\mathrm{UB}_{2}$ and inter-granular UCO regions. The microstructure in Figure $4 \mathrm{C}$ was produced after sintering for 1 hour at $1800^{\circ} \mathrm{C}$ due to the relatively high melting point of $\mathrm{UB}_{2}$, as opposed to the silicide and composite materials which were sintered at $1400^{\circ} \mathrm{C}$. It is likely that higher density could be achieved with longer hold times and/or higher sintering temperatures, but this was beyond the scope of the present study.

\subsubsection{Short-Exposure Materials}

In order to understand the change in steam-response observed during TGA, fragments of $\mathrm{U}_{3} \mathrm{Si}_{2}$ and $50 \mathrm{wt} \%$ composite material were exposed to steam for five minutes at fixed temperatures, below that at which they were expected to pulverise. $\mathrm{U}_{3} \mathrm{Si}_{2}$ was exposed at $465^{\circ} \mathrm{C}$ and composite mateiral was exposed at $465^{\circ} \mathrm{C}$ and $565^{\circ} \mathrm{C}$.

Following five minute exposures at $465^{\circ} \mathrm{C}$, there appears to be a clear difference in silicon behaviour between $\mathrm{U}_{3} \mathrm{Si}_{2}$ and composite material. Figure 6 shows the exposed surface of a $\mathrm{U}_{3} \mathrm{Si}_{2}$ fragment with both SEM and EDX maps for the location of silicon, uranium and oxygen. The top right of the images within Figure 6 show material which has broken away from the 


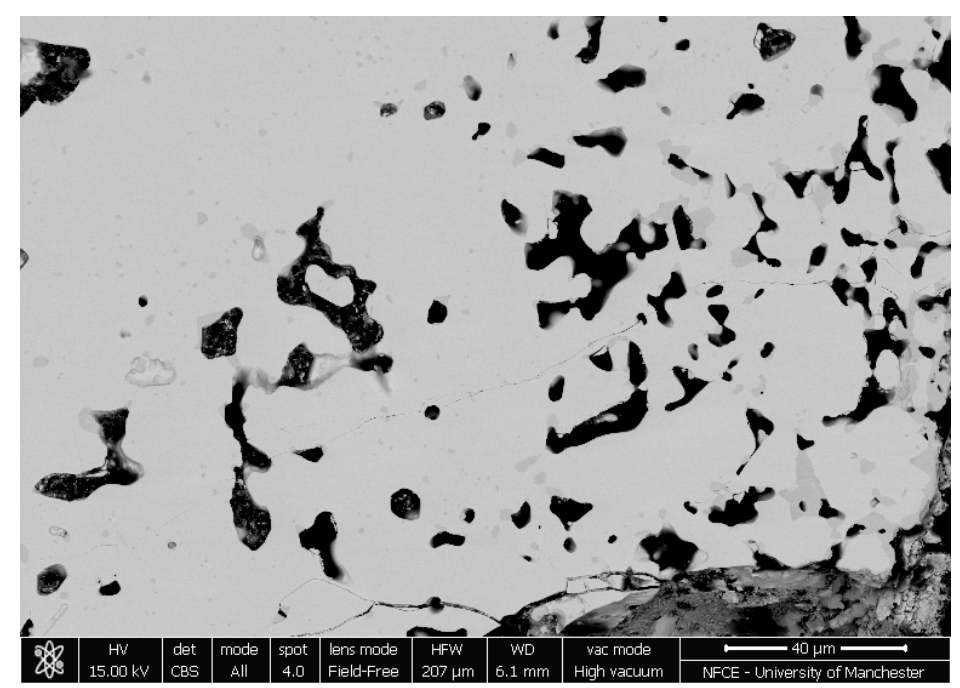

Figure 5: Band of porosity visible adjacent to surface of $\mathrm{U}_{3} \mathrm{Si}_{2}$.

bulk surface, which appears to have fractured behind the oxide layer, exposing more silicidecontaining material. Within the bulk of the fragment, silicon rich regions are forming at a sharp edge to the existing oxide layer. These silicon rich regions are similar in size and morphology to cracks which appear to develop at later stages of the reaction, as seen on Figure 8, which also shows striations typical of hydride formation, and an area of $\mathrm{UO}_{2}$ containing a very large number of cracks. Each of the individual silcide pieces visible in Figure 8 is surrounded by oxide, which appears to progress from the cracks inwards, further displacing Si. Similar morphology is visible on parts of the fractured material in Figure 6, which culminates in a further silicon-rich small central region, completely surrounded by stable oxide.

In contrast, Figure 7 shows an open crack on the surface of a 50wt\% composite fragment. Here silicon rich regions appear to form in bands across the $\mathrm{U}_{3} \mathrm{Si}_{2}$ grain towards nearby $\mathrm{UB}_{2}$ grains. The existing crack has a layer of $\mathrm{UO}_{2}$ directly adjacent to it, similar to those which have formed adjacent to cracks on $\mathrm{U}_{3} \mathrm{Si}_{2}$ shown on Figure 8. No silicon rich regions were observed forming at grain boundaries, although they are do appear to form at the centre of heavily oxidised grains.

Following exposure to $565{ }^{\circ} \mathrm{C}$ steam, small solid fragments of $50 \mathrm{wt} \%$ composite remained, although a large proportion of the original sample had formed $\mathrm{UO}_{2}$ powder. Representative images from the edge of these solid fragments are shown in Figure 9 and Figure 10. At this temperature, which is within the rapid mass gain phase seen in Figure 2 for these samples, silicide grains within the bulk can be seen to have begun to oxidise. In contrast to the slow inward growth of oxide seen at lower temperatures, in Figure $9 \mathrm{UO}_{2}$ appears to form as striations across the silicide material, possibly due to the distortions caused by the formation of the $\mathrm{U}_{3} \mathrm{Si}_{2} \mathrm{H}_{2}$ phase. $\mathrm{UB}_{2}$ grains can be seen to have broken away from the bulk of the sample, and but show limited oxidative attack at this temperature.

It can be seen in Figure 10 that layers of material have been removed from the sample, but appear to have maintained cohesion and form a solid single layer. EDX suggests that oxygen has begun to attack silicide within the layers, but not caused the breakaway of small individual 


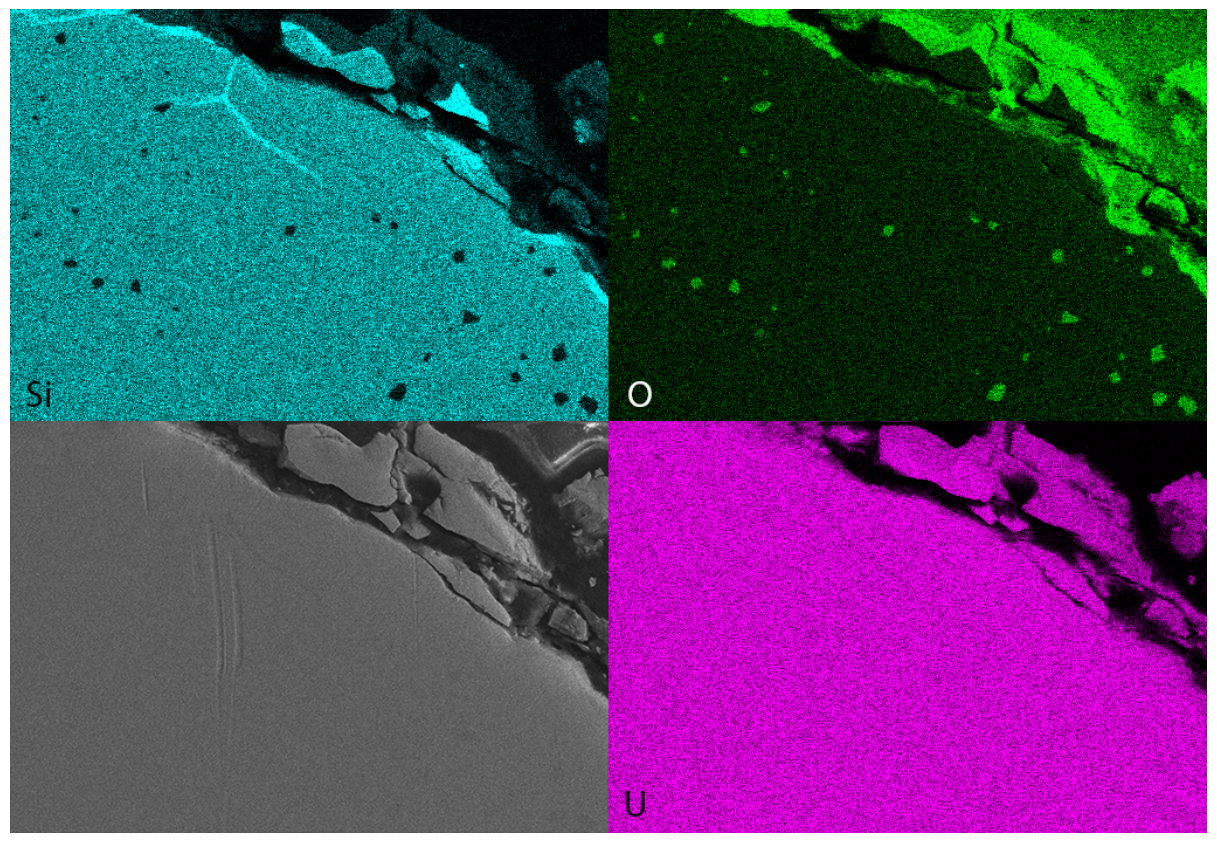

Figure 6: $\mathrm{SEM}$ and EDX of $\mathrm{U}_{3} \mathrm{Si}_{2}$ after short exposure to steam at $465^{\circ} \mathrm{C}$

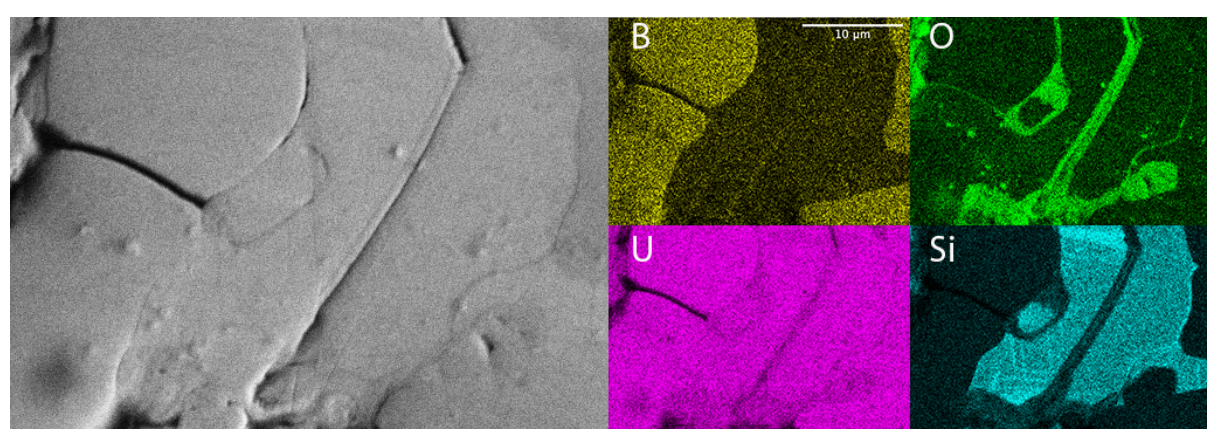

Figure 7: SEM and EDX of $\mathrm{UB}_{2} / \mathrm{U}_{3} \mathrm{Si}_{2}$ composite after short exposure to steam at $465^{\circ} \mathrm{C}$ 


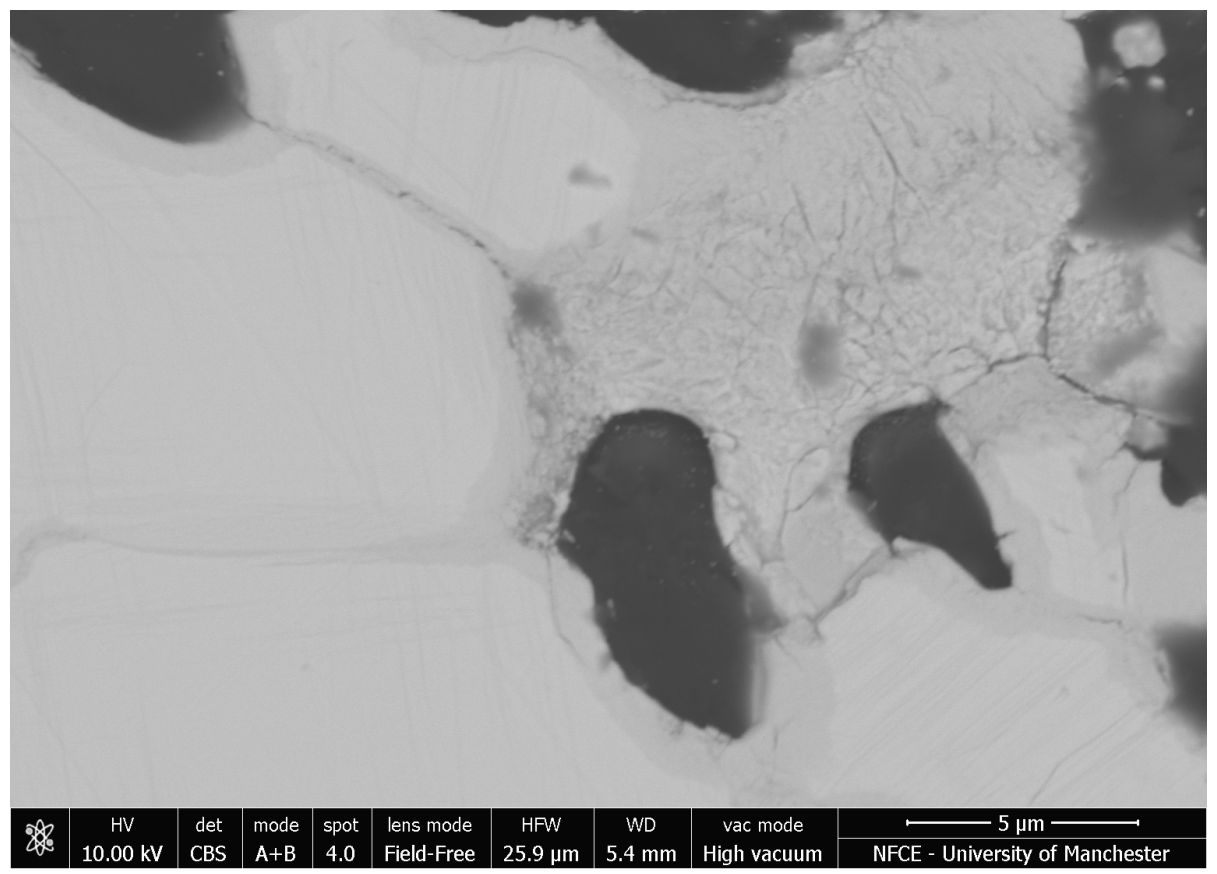

Figure 8: SEM image of $\mathrm{U}_{3} \mathrm{Si}_{2}$ after short exposure to steam at $465^{\circ} \mathrm{C}$, this region appears to have corroded more than that shown in Figure 6 and cracks are visible at several points, exposing all sides of the silicide grains.

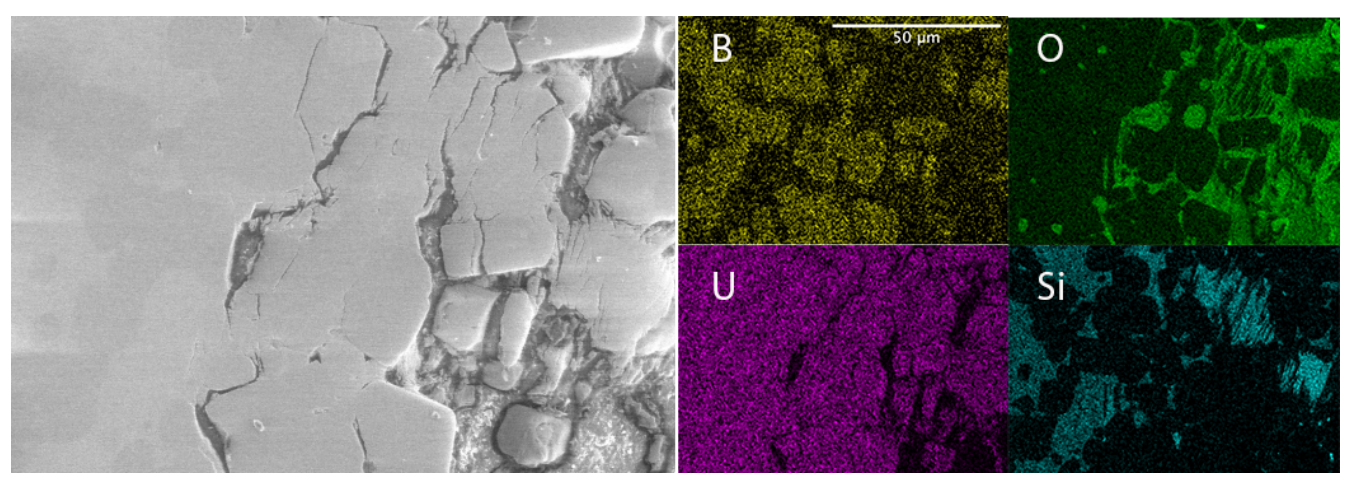

Figure 9: SEM and EDX image of 50wt $\%$ composite fragment after exposure to $565^{\circ} \mathrm{C}$ steam for five minutes. 


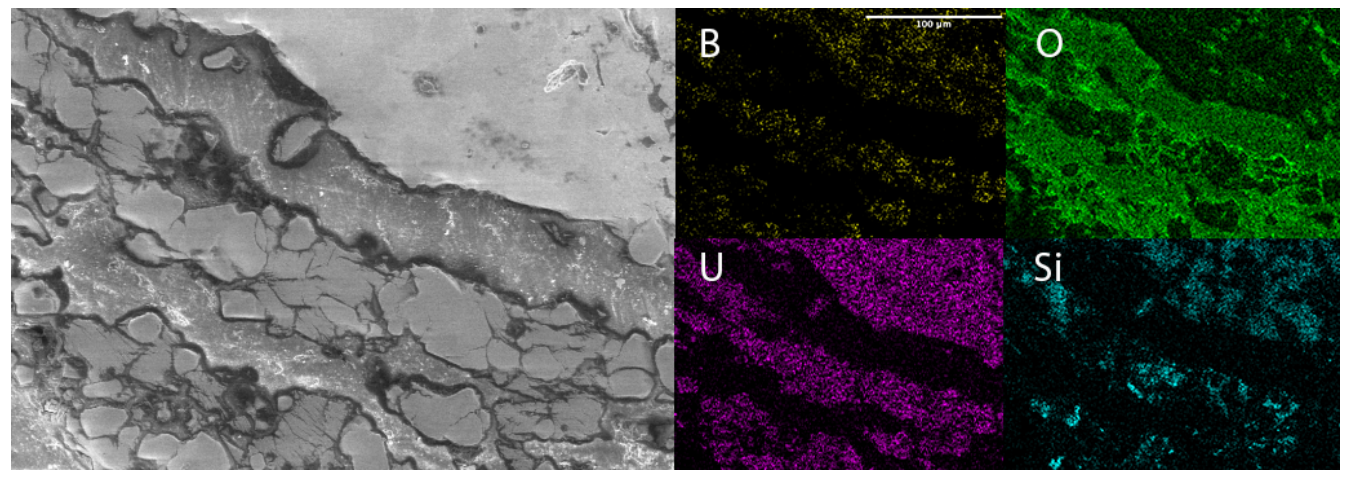

Figure 10: Low magnification SEM and EDX image of 50wt $\%$ composite fragment after exposure to $565^{\circ} \mathrm{C}$ steam for five minutes. The high oxygen content between the uranium bearing layers is a result of the resin used to mount the sample.

grains seen in on $\mathrm{U}_{3} \mathrm{Si}_{2}$.

\subsubsection{Powder Morphology Following $900^{\circ} \mathrm{C}$ Steam}

In all cases following exposure to $900^{\circ} \mathrm{C}$ steam, samples were reduced to powder which was confirmed to be $\mathrm{UO}_{2}$ via XRD. SEM micrographs of the final powder products are shown in Figure 11.

Figure 11 A shows $\mathrm{UO}_{2}$ formed by reacting $\mathrm{U}_{3} \mathrm{Si}_{2}$ with steam. In contrast to the $\mathrm{UB}_{2}$-steam reaction (Figure $11 \mathrm{~B}$ ), it shows a large number of branching cracks on all surfaces, creating a large surface area. Figure $11 \mathrm{C}$ is the result of reacting a $50 \mathrm{wt} \%$ composite with steam, and shows a limited number of branching cracks, although some are present on exposed surfaces. Figure $11 \mathrm{D}$ shows a backscattered image of a $50 \mathrm{wt} \%$ composite following steam exposure. The dark regions visible within the grain were identified via EDX as a boron-silicon mixture, which was observed on several similar powder grains, often visible towards the centre of crystallites. Visually it appears that at later stages of the reaction, $\mathrm{UO}_{2}$ forms a semi-stable surface around a 'core' of lighter elements, which do not react further. It is possible therefore that light elements are not seen on XRD after steam exposure due to limited penetration of X-rays into uraniumbearing phases. Estimated penetration of a typical XRD X-ray to $\mathrm{UO}_{2}$ is around $6 \mu \mathrm{m}$, and would not reach the centre of the features seen on Figure $11 \mathrm{D}$.

\section{Discussion}

The addition of a significant mass of $\mathrm{UB}_{2}$ to $\mathrm{U}_{3} \mathrm{Si}_{2}$ greatly increases the temperature at which it begins to rapidly react. From TGA, this effect is beyond that which would be expected if the material was partially reacting at lower temperatures, for example due to the lower mass fraction of $\mathrm{U}_{3} \mathrm{Si}_{2}$ present within the material. Indeed, there is no measurable increase in mass at the temperatures at which complete pulverisation of $\mathrm{U}_{3} \mathrm{Si}_{2}$ is observed.

The mechanism by which this improvement is achieved requires further understanding of the $\mathrm{U}_{3} \mathrm{Si}_{2}$-steam reaction; it cannot be explained if the formation of $\mathrm{U}_{3} \mathrm{Si}_{2} \mathrm{H}_{2}$ is the sole reason for the early onset and energetic nature of the reaction, as has been theorised by Sooby Wood amongst others [2]. 


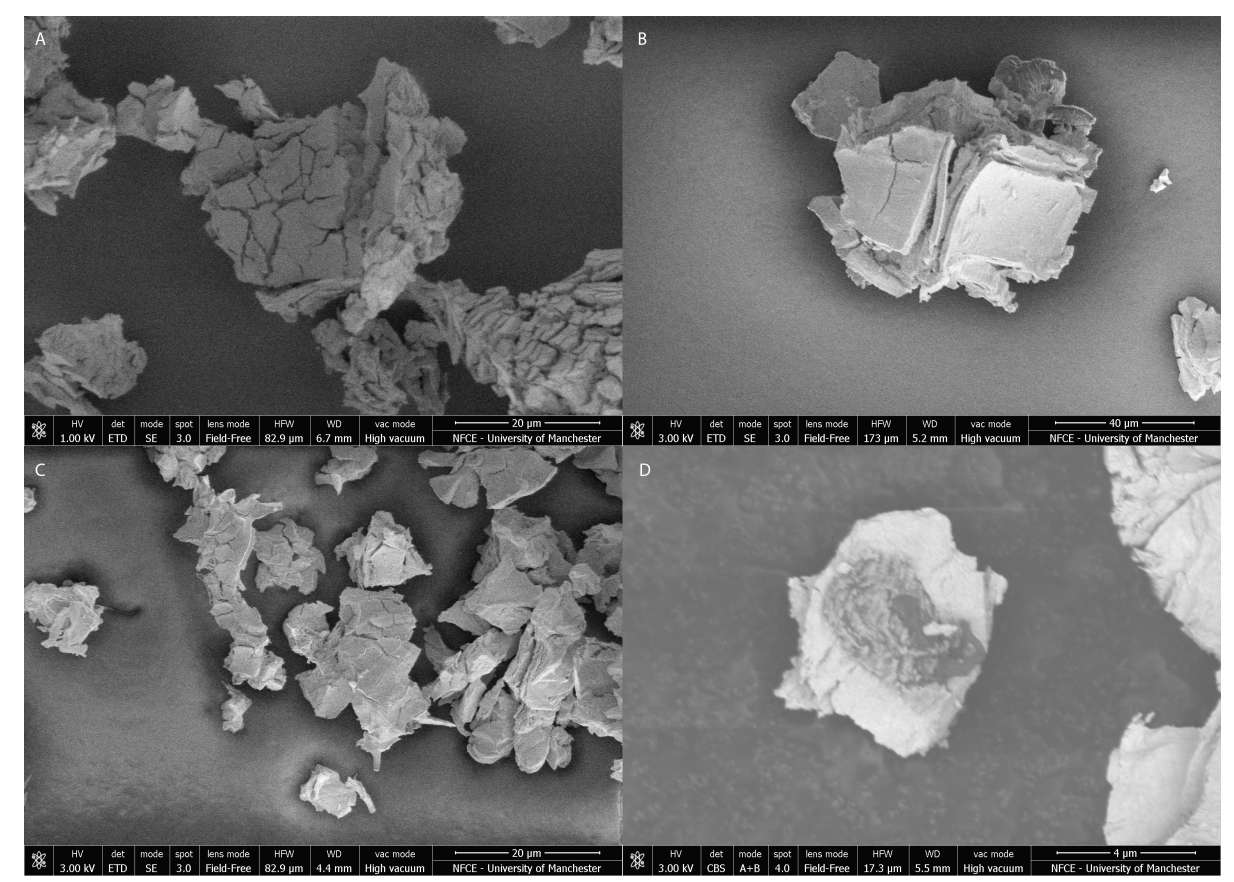

Figure 11: SEM Micrographs of powder produced from following steam tests of; $A-\mathrm{U}_{3} \mathrm{Si}_{2}, \mathrm{~B}-\mathrm{UB} 2, \mathrm{C}-50 \mathrm{wt} \%$ composite, D - 50wt\% composite

As previously discussed in the literature, this is a complex reaction which is known to at least partially result from the formation of a $\mathrm{U}_{3} \mathrm{Si}_{2} \mathrm{H}_{2}$ phase, that is theorised to lead to rapid oxidation due to the distortion of the $\mathrm{U}_{3} \mathrm{Si}_{2}$ lattice. Within the present work we have observed similar striations on silicide material exposed to high temperature steam, both in composite and reference $\mathrm{U}_{3} \mathrm{Si}_{2}$ material, and so consider the present work to show good agreement with literature in this respect.

However, microscopy of $\mathrm{U}_{3} \mathrm{Si}_{2}$ exposed to steam at $465^{\circ} \mathrm{C}$ shows the formation of silicon rich regions which closely resemble the morphology of cracks observed at high temperatures, and appear to follow grain boundaries. From the separated silicide/oxide grains visible on the same observations, we suggest that these may form failure points which expose large regions of unreacted silicide material for further reactions. The presence of large amounts of silicide within the material removed from the bulk appears to preclude this relating solely to the spallation of an oxide layer formed on the surface.

One proposed mechanism by which this might occur is through the production of volatile or brittle silicon compounds at grain boundaries. There are numerous Si-O-H compounds which would be volatile at the required temperatures. This would also go some way towards explaining the limited silicon observed in the end products of the steam reaction, and the energy at which material has been seen to eject from apparatus during silicide steam reactions. However, cracks at the silicide surface and removed mixed oxide/silicide material were much more commonly observed than silicon-rich structures within the bulk. Although the morphology of cracks open to the surface is similar to that of the silicon-rich regions which were observed, we acknowledge that further work is certainly required to demonstrate this mechanism, particularly given the current 
importance of the steam-silicide reaction for the deployment of accident tolerant fuels. The absence of silicon compounds following oxidation silicide in both air and steam is an ongoing challenge for the understanding of this important mechanism [10, 2, 11].

An alternative mechanism is through the formation of borosilicate glass on the material surface. This would likely be resistant to steam corrosion up until its melting point, typically around $500-600{ }^{\circ} \mathrm{C}$. No such layer was observed via high-magnification SEM and EDX, but this does not preclude the presence of such a feature, instead setting an upper limit on its thickness to be below that detectable via SEM (around $500 \mathrm{~nm}$ ). Silicon does appear to diffuse toward boride grains within composite pellets which would provide the requisite materials for the formation of a borosilicate layer alongside oxygen.

Given the complex nature of the silicide-steam reaction, it is not surprising that the mechanism by which $\mathrm{UB}_{2}$ improves upon this appears to be complex and is not yet fully understood. Although the rapid rate of reaction has previously been linked with hydride formation, interrupting this process does not appear to be the mechanism by which the composite limits degradation, as hydride-striations were regularly observed on post-exposure silicide grains within the composite.

The addition of a significant weight percentage of $\mathrm{UB}_{2}$ to $\mathrm{U}_{3} \mathrm{Si}_{2}$ does appear to prevent the formation of a large number of cracks within the material as seen at low and high temperature exposures as well as the powder produced following $900^{\circ} \mathrm{C}$ exposure. Although it does not prevent their formation altogether, it limits their number significantly, preventing a rapid increase in surface area.

This may be related to the behaviour of silicon during the composite reaction, which was seen to form multiple bands of silicon rich material across silicide grains within the composite material. Grains in which these bands were observed also showed striations which were taken to show the formation of the $\mathrm{U}_{3} \mathrm{Si}_{2} \mathrm{H}_{2}$ phase and it is proposed that silicon displaced by the oxidation reaction at the surface is able to occupy sites within the $\mathrm{U}_{3} \mathrm{Si}_{2} \mathrm{H}_{2}$ lattice more easily than at a $\mathrm{U}_{3} \mathrm{Si}_{2} / \mathrm{UB}_{2}$ boundary.

At higher temperatures, these bands develop into mixed oxide-silicide grains. It has been previously established that the introduction of hydrogen to the $\mathrm{U}_{3} \mathrm{Si}_{2}$ distorts the lattice, causing significant swelling and allowing oxygen ingress more easily [12]. We therefore suggest that the mixed-grains observed are a result of oxygen occupying the lowest energy sites first. It is not clear where the displaced silicon from this reaction relocates to, although it has not been detected in either reference material or composite exposed to $900^{\circ} \mathrm{C}$.

We theorise that the diffusion of silicon within the grain, rather than to the grain boundary, acts to increase the amount of surface oxidation (and hence silicon displacement) required to form regions to open into cracks later in the process. Further work is clearly required to understand this mechanism and the underlying silicide-steam reaction in greater detail.

It is also clear that $\mathrm{UB}_{2}$ grains within the composite are largely unaffected by steam at temperatures at which $\mathrm{U}_{3} \mathrm{Si}_{2}$ is converted to $\mathrm{UO}_{2}$. Although little data exists on this material, predictions of its behaviour and thermal properties are extremely encouraging, and the results presented here suggests that it may offer significant improvements to the resistance of U3Si2 to oxidation as a result of fuel-coolant interactions.

\section{Conclusions}

A number of composite $\mathrm{U}_{3} \mathrm{Si}_{2} / \mathrm{UB}_{2}$ pellets were produced and their performance tested in high temperature steam. The addition of small amounts $(10 \mathrm{wt} \%)$ of $\mathrm{UB}_{2}$ to $\mathrm{U}_{3} \mathrm{Si}_{2}$ increases 
the onset temperature of the steam reaction by around $100{ }^{\circ} \mathrm{C}$, and the addition of $50 \mathrm{wt} \% \mathrm{UB}_{2}$ maintains this increase while limiting the amount of material ejected from the crucible. Both $\mathrm{UB}_{2}$ and the composites tested here appear to offer substantial advantages over $\mathrm{U}_{3} \mathrm{Si}_{2}$ as an accident tolerant fuel for light water reactors.

Boron enrichment is a well established technology, hence the availability of boron depleted in boron-10 offers the prospect of both an acceptable neutronic performance and the means of incorporating an integral burnable absorber within the fuel.

\section{Acknowledgements}

The time and material to perform this study were funded by the Dalton Nuclear Institute at the University of Manchester.

\section{References}

[1] Edward J. Lahoda. Development of LWR Fuels with Enhanced Accident Tolerance. Technical report, 2015.

[2] E. Sooby Wood, J.T. White, C.J. Grote, and A.T. Nelson. U3Si2 behavior in H2O: Part I, flowing steam and the effect of hydrogen. Journal of Nuclear Materials, 501:404-412, 2018.

[3] K.J. McClellan, D.D. Byler, E.P. Luther, J.T. White, and P. Medvedev. ATF-1 UN-U3Si5 Composite Fuel Development and Irradiation Test Design. In FY2014 Ceramic Fuels Development Annual Highlights, pages 36-40, 2014.

[4] Ericmoore Jossou, Linu Malakkal, Barbara Szpunar, Dotun Oladimeji, and Jerzy A. Szpunar. A first principles study of the electronic structure, elastic and thermal properties of UB2. Journal of Nuclear Materials, 490:41-48, jul 2017.

[5] V. S. (Vasili Semenovich) Emelianov and A. I. Evstiukhin. The metallurgy of nuclear fuel : properties and principles of the technology of uranium, thorium, and plutonium.

[6] P.A. Burr, E. Kardoulaki, R. Holmes, and S.C. Middleburgh. Defect evolution in burnable absorber candidate material: Uranium diboride, UB2. Journal of Nuclear Materials, 513:45-55, jan 2019.

[7] J. Turner, J. Buckley, G. Phillips, and T. J. Abram. The use of gadolinium as a burnable poison within U3Si2 fuel pellets. Journal of Nuclear Materials, 509:204-211, 2018

[8] Jason M. Harp, Paul A. Lessing, and Rita E. Hoggan. Uranium silicide pellet fabrication by powder metallurgy for accident tolerant fuel evaluation and irradiation. Journal of Nuclear Materials, 466:728-738, 2015.

[9] J.D. Turner, S.C. Middleburgh, and T.J. Abram. A high density composite fuel with integrated burnable absorber: U3Si2-UB2. Journal of Nuclear Materials, In Press.

[10] E. Sooby Wood, J. T. White, and A. T. Nelson. Oxidation behavior of U-Si compounds in air from 25 to $1000 \mathrm{C}$. Journal of Nuclear Materials, 484:245-257, 2017.

[11] E. Sooby Wood, J. T. White, and A. T. Nelson. The effect of aluminum additions on the oxidation resistance of U3Si2. Journal of Nuclear Materials, 489:84-90, 2017.

[12] S.C. Middleburgh, A. Claisse, D.A. Andersson, R.W. Grimes, P. Olsson, and S. Mašková. Solution of hydrogen in accident tolerant fuel candidate material: U3Si2. Journal of Nuclear Materials, 501:234-237, apr 2018. 